\title{
Somatostatin Contributes to In Vivo Gamma Oscillation Modulation and Odor Discrimination in the Olfactory Bulb
}

\author{
Gabriel Lepousez, ${ }^{1,2}$ Aurélie Mouret, ${ }^{3}$ Catherine Loudes, ${ }^{1,2}$ Jacques Epelbaum, ${ }^{1,2}$ and Cécile Viollet ${ }^{1,2}$ \\ ${ }^{1}$ Inserm, Unité Mixte de Recherche 894, Centre de Psychiatrie et Neuroscience, and 2Université Paris Descartes, Faculté de Médecine, F-75014 Paris, France, \\ and ${ }^{3}$ Perception and Memory Unit, Centre National de la Recherche Scientifique, Unité de Recherche Associée 2182, Institut Pasteur, F-75015 Paris, France
}

Neuropeptides are systematically encountered in local interneurons, but their functional contribution in neural networks is poorly documented. In the mouse main olfactory bulb (MOB), somatostatin is mainly concentrated in local GABAergic interneurons restricted to the external plexiform layer (EPL). Immunohistochemical experiments revealed that the sst2 receptor, the major somatostatin receptor subtype in the telencephalon, is expressed by mitral cells, the MOB principal cells. As odor-activated mitral cells synchronize and generate gamma oscillations of the local field potentials, we investigated whether pharmacological manipulations of sst2 receptors could influence these oscillations in freely behaving mice. In wild-type, but not in sst2 knock-out mice, gamma oscillation power decreased lastingly after intrabulbar injection of an sst2-selective antagonist (BIM-23627), while sst2-selective agonists (octreotide and L-779976) durably increased it. Sst2-mediated oscillation changes were correlated with modifications of the dendrodendritic synaptic transmission between mitral and granule cells. Finally, bilateral injections of BIM-23627 and octreotide respectively decreased and increased odor discrimination performances. Together, these results suggest that endogenous somatostatin, presumably released from EPL interneurons, affects gamma oscillations through the dendrodendritic reciprocal synapse and contributes to olfactory processing. This provides the first direct correlation between synaptic, oscillatory, and perceptual effects induced by an intrinsic neuromodulator.

\section{Introduction}

Since the pioneer work of Adrian (1942), gamma oscillations $(40-100 \mathrm{~Hz})$ of the local field potentials (LFP) have attracted much interest in the main olfactory bulb (MOB). Disruption of these oscillations in knock-out mice alters odor discrimination (Nusser et al., 2001). Conversely, gamma oscillations are increased when rats perform a fine odor discrimination task (Beshel et al., 2007). Induced by odorants, these LFP oscillations are intrinsic to the MOB (Neville and Haberly, 2003). Experimental and computational studies have underlined the key role of reciprocal dendrodendritic interactions between mitral cells and local interneurons in their generation (Lledo and Lagier, 2006; Kay et al., 2009). This excitatory-inhibitory microcircuit mediates recurrent and lateral inhibition, which in turn synchronizes neural activity and results in fast oscillations of the LFP. This emergent property of the olfactory network is thought to shape odorant receptive fields and to control the precise firing of the principal neurons for downstream reading (Lledo and Lagier, 2006; Kay et al., 2009).

The MOB receives extrinsic neuromodulatory inputs that affect these oscillatory dynamics and consequently olfactory pro-

Received 0ct. 6, 2009; revised Nov. 27, 2009; accepted Dec. 1, 2009.

This work was supported by the Institut National de la Santé et de la Recherche Médicale (Inserm). G.L. and A.M. are recipients of a fellowship from the French Ministère de l'Education Nationale et de la Recherche. We are grateful to Frédérique Poindessous-Jazat, Vincent Villette, and Zsolt (saba for technical help, Lone Helboe for the gift of the sst2A antiserum, Susan Rohrer (Merck Research Laboratories, Rahway, NJ) for the gift of L-779976, Michael Culler (Biomeasures, IPSEN Group, Milford, MA) for the gift of BIM-23627, Herbert Schmid (Novartis, Basel, Switzerland) for the gift of octreotide, and Gilles Gheusi for helpful discussions.

Correspondence should be addressed to Cécile Viollet, Inserm, Unité Mixte de Recherche 894, Centre de Psychiatrie et Neuroscience, 2 ter rue d'Alésia, F-75014 Paris, France. E-mail: cecile.viollet@inserm.fr.

DOI:10.1523/JNEUROSCI.4958-09.2010

Copyright $\odot 2010$ the authors $\quad 0270-6474 / 10 / 300870-06 \$ 15.00 / 0$ cessing. In vitro, cholinergic transmission excites mitral cells and inhibits granule cells (Castillo et al., 1999; Ghatpande and Gelperin, 2009). In vivo pharmacological blockade of cholinergic tone is associated with changes in gamma oscillations (Tsuno et al., 2008), odor receptive fields of mitral cells, and olfactory behavior (Chaudhury et al., 2009). Similarly, application of noradrenergic agonists excites mitral cells and enhances gamma oscillations (Gire and Schoppa, 2008), whereas inhibition of noradrenergic receptors impairs olfactory perception and memory (Mandairon et al., 2008). Beside these extrinsic neuromodulatory processes that involve long-range centrifugal fibers, little is known about the intrinsic regulation of network oscillations by endogenous components of the olfactory circuitry. Neuropeptides, present in local interneurons and released after highfrequency stimulations (Vezzani and Hoyer, 1999; Baraban and Tallent, 2004), could act as intrinsic network modulators. In mice, the neuropeptide somatostatin is concentrated in a subset of external plexiform layer (EPL) interneurons (Lepousez et al., 2010). These interneurons receive high-frequency inputs from mitral cells (Hamilton et al., 2005), which provide a favorable context for peptide release. So far, somatostatin effects on network oscillations have been observed in the hippocampus and the thalamus, and may result from a modulation of membrane conductance and synaptic properties (Olias et al., 2004; Viollet et al., 2008).

In the present work, after demonstrating that mitral cells express the somatostatin receptor 2 (sst2), we performed local injections of sst2-selective ligands in wild-type and sst 2 knock-out mice, to evaluate in vivo how these receptors affect gamma oscillations. We then investigated sst2-mediated modulation of the 

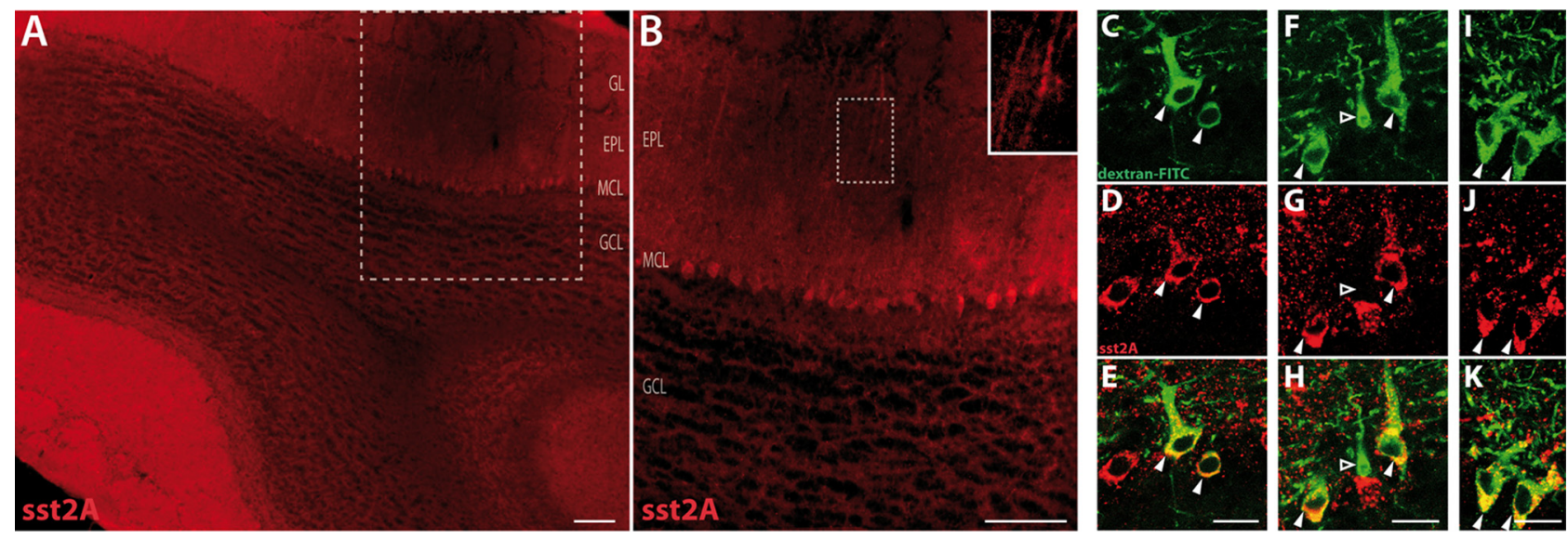

Figure 1. Agonist-induced internalization of sst2A receptors reveals their cellular localization in mitral cells. $A$, From a basal diffuse sst2 labeling in the EPL and GL, agonist injection in the EPL induces the appearance of sst2A-immunoreactive cells in the $\mathrm{MCL}$ around the injection site (boxed region). $\boldsymbol{B}$, At higher magnification, we observe the clustering and accumulation of sst2A receptors in thick dendritic processes perpendicular to the EPL (inset) and in large somata in the MCL. $\mathbf{C} \boldsymbol{K}$, Injection of dextran-FITC (green) in the GL anterogradely labels large mitral cell bodies in the MCL (arrowheads), from which a single large primary dendrite extends into the EPL. Rarely, small interneuron somata are also labeled (open arrowheads). After internalization, all tracer-labeled mitral cells are sst2A-immunopositive (red) and tracer-labeled interneurons are sst2A-immunonegative. Scale bars: $\boldsymbol{A}, \boldsymbol{B}, 100 \mu \mathrm{m} ; \boldsymbol{C}-\boldsymbol{K}, 20 \mu \mathrm{m}$. GCL, Granule cell layer.

dendrodendritic synaptic transmission and olfactory discrimination performances.

\section{Materials and Methods}

Animals. Two- to five-month-old sst2 knock-out mice, their wild-type littermates (backcrossed to the C57BL/6J background for 12 generations) (Zheng et al., 1997), and C57BL/6J mice (Janvier) were housed individually on a $12 \mathrm{~h}$ light/dark cycle with ad libitum access to food and water. All procedures were approved by a local ethical committee, in accordance with the European Communities Council Directive (86/609/EU).

Quantitative RT-PCR. Olfactory bulb total RNA was extracted and reverse transcribed $(0.5 \mu \mathrm{g})$. Real-time $\mathrm{qPCR}$ was performed with an $\mathrm{ABI}$ Prism 7000 Sequence Detection System (Applied Biosystems). Amplification was performed using Taqman Universal Master Mix kit for sst2A (Mm03015782-S1), sst2B (Mm00436685-g1), and 18S rRNA as internal control (see supplemental Methods, available at www.jneurosci.org as supplemental material).

Stereotaxic injections. Under ketamine/xylazine anesthesia (100/10 $\mathrm{mg} / \mathrm{kg}$, i.p.), $0.25 \mu \mathrm{l}$ of octreotide $(0.5 \mathrm{~mm}$, Novartis) or saline $(0.9 \%$ $\mathrm{NaCl})$ were injected through a glass micropipette $(0.1 \mu \mathrm{l} / \mathrm{min})$, positioned into the medial EPL (stereotaxic coordinates: AP, +5.1 from bregma; ML, $+0.4 ; \mathrm{DV},+1.5$ from brain surface). Animals recovered for 30 min, then were deeply anesthetized and transcardially perfused with Zamboni fixative (4\% paraformaldehyde, $0.2 \%$ picric acid in $0.1 \mathrm{M}$ phosphate buffer). Brains were quickly removed, cryoprotected in $30 \%$ sucrose for $24 \mathrm{~h}$, frozen in ice-cold isopentane, and stored $\left(-80^{\circ} \mathrm{C}\right)$. For dextran-FITC injection (FD70S, Sigma; $7 \%$ diluted in $0.9 \% \mathrm{NaCl}$ ), anesthetized animals were first injected with $0.1 \mu \mathrm{l}$ of tracer in the medial glomerular layer $(\mathrm{AP},+5.1$; $\mathrm{ML},+0.1$; $\mathrm{DV},+1.5)$, recovered for $7 \mathrm{~h}$, were injected with octreotide, and were perfused $1 \mathrm{~h}$ later.

Immunohistochemistry. Immunofluorescence labeling was performed using a characterized rabbit sst2A antiserum (Csaba et al., 2007). The signal was revealed using biotin-streptavidin CY3 complex (Fig. 1A,B) or amplified using the tyramide amplification system (Fig. $1 C-K$ ) (see supplemental Methods, available at www.jneurosci.org as supplemental material).

In vivo $L F P$ recordings. Oscillatory and evoked LFPs were recorded in the EPL using a bipolar electrode $(0.2-0.5 \mathrm{M} \Omega$; reference electrodes to the skull) closely linked to a cannula. For lateral olfactory tract (LOT) stimulation, paired square current pulses (interstimulus interval: $30 \mathrm{~ms}$ ) were applied every $50 \mathrm{~s}$ with a similar electrode inserted in the LOT. Signals were amplified and sampled using a 1401 acquisition interface and Spike2 software (CED). During the recordings, mice remained in their home cage and showed active exploration with intense sniffing activity. Signals were continuously recorded from $40 \mathrm{~min}$ before to $120 \mathrm{~min}$ after intrabulbar injection of $0.4 \mu \mathrm{l}$ of BIM-23627 (2 mM, Biomeasures), octreotide (2 mM), L-779976 (2 mM, Merck Research Laboratories), or vehicle $(0.9 \% \mathrm{NaCl})$. Doses were chosen based on previous reports (Bassant et al., 2005; Gastambide et al., 2009). Each mouse received the three compounds at $3 \mathrm{~d}$ intervals, in a random order. The fast Fourier transform algorithm was used to measure the absolute spectral power and the mean frequency of gamma $(40-100 \mathrm{~Hz})$, beta $(15-40 \mathrm{~Hz})$, and theta $(2-12 \mathrm{~Hz})$ bands. Absolute values were normalized to the total power of the spectrum and to the mean basal value (set at 1). For LOT-evoked LFPs, measured peak amplitudes were normalized to baseline and to the mean basal value (set at 1) (see supplemental Methods, available at www. jneurosci.org as supplemental material).

Odor discrimination task. Mice were first implanted with two cannulae on top of the MOB. One week after surgery, they were trained using an operant conditioning go/no-go procedure in home-made computercontrolled olfactometers. In this paradigm, the presence of the positive odor stimulus $(\mathrm{S}+)$ was associated with a water reward obtained by licking a water delivery tube. For the negative odor stimulus $(\mathrm{S}-)$, mice received no water reward and had to refrain from licking. In each trial, a single stimulus ( $\mathrm{S}+$ or $\mathrm{S}-$ ) was presented, and the percentage of correct responses was determined for each block of 20 trials. All mice underwent a session of 10 blocks per day. Once mice reached $85 \%$ of correct responses, daily sessions were preceded by a bilateral injection of $1 \mu \mathrm{l}$ of BIM-23627 (2 mM), octreotide (2 mM), or vehicle (mean injection delay before performing the task: $37 \pm 1 \mathrm{~min}$ ). Olfactory discrimination performances were determined with monomolecular odor compounds and binary odor mixtures (Sigma) (see supplemental Methods, available at www.jneurosci.org as supplemental material).

\section{Results}

\section{Mitral cells express the sst2 receptor}

In mice olfactory bulb, the sst 2 receptor subtype exists as two splice variants: sst2A, the major full-length form, predominates over sst2B, the minor $\mathrm{C}$ terminus spliced form (sst2A/sst2B mRNA ratio: $32.7 \pm 1.3 ; n=3$ ). In rodent brain, sst $2 \mathrm{~A}$ receptors are targeted to the plasma membrane on somatodendritic processes resulting in a diffuse sst $2 \mathrm{~A}$ immunolabeling, but in vivo agonist stimulation induces rapid (in the order of minutes) internalization and clustering of receptors into the soma (Csaba et al., 2007). Thirty minutes after octreotide injection in the medial EPL (Fig. 1A), sst2A receptor immunoreactivity was concentrated in large cell bodies $(\sim 20 \mu \mathrm{m}$ diameter $)$ in the mitral cell layer (MCL) (Fig. $1 B)$ and in large dendrites $(\sim 1 \mu$ m diameter) perpendicular to the layer (Fig. $1 B$, inset). The laminar distribu- 

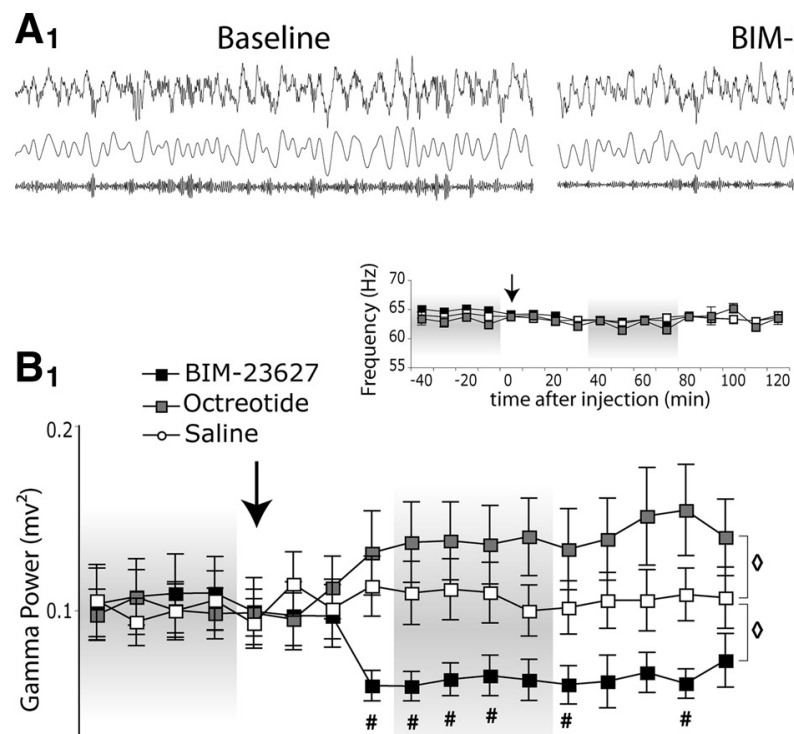

pre
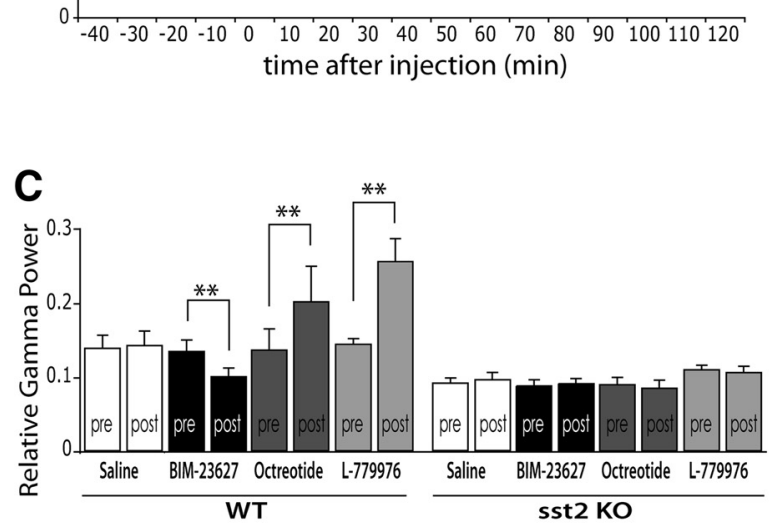

BIM-23627

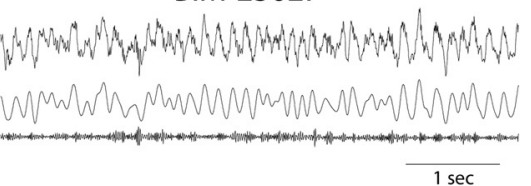

$1 \mathrm{sec}$
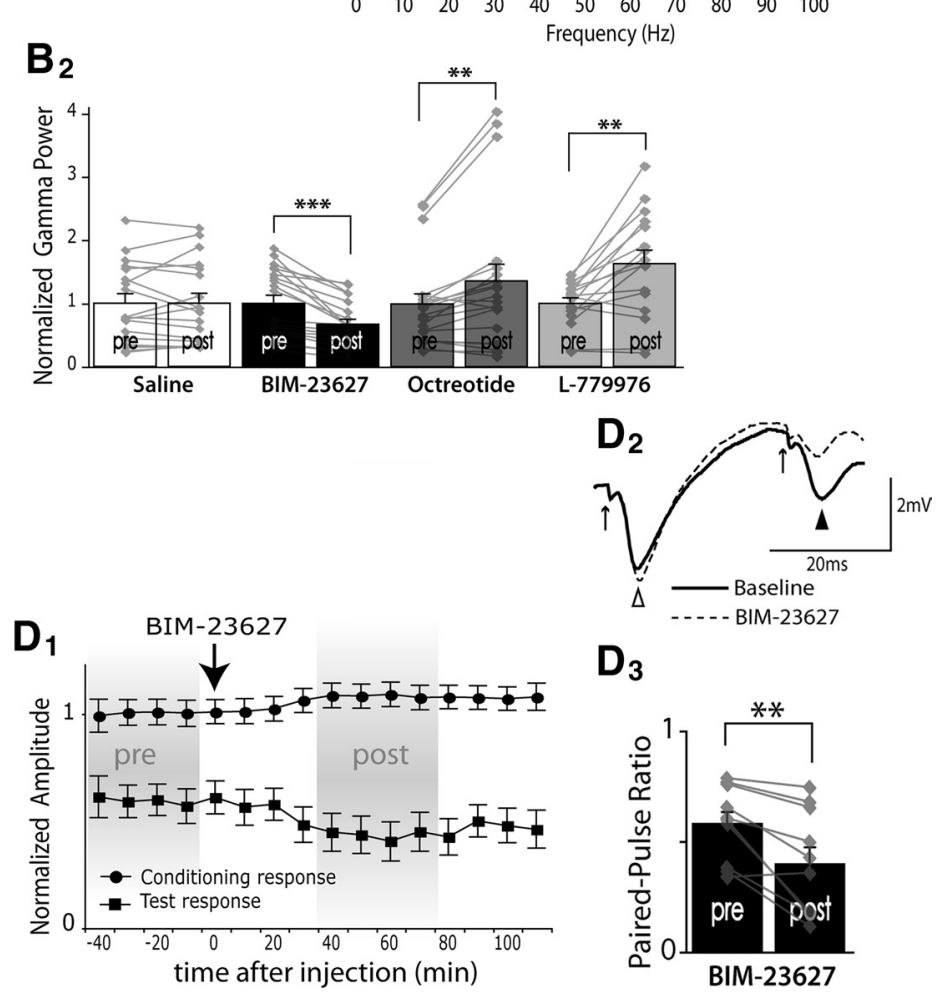

$\mathrm{D}_{3}$

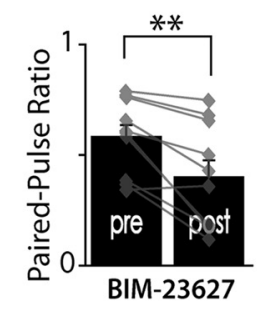

Figure 2. sst2 receptors modulate in vivo gamma oscillation power and dendrodendritic transmission. $A_{1}$, Examples of raw (top traces), filtered theta ( $0-12 \mathrm{~Hz}$, middle traces), and filtered gamma ( $40-100$ $\mathrm{Hz}$, bottom traces) LFPs before ("baseline", left) and $40 \mathrm{~min}$ after (right) injection of BIM-23627. $A_{2}$, Power spectra, showing the decrease of gamma power in the MOB 40 min after BIM-23627 injection (inset, enlarged $40-100 \mathrm{~Hz}$ frequency band). Note the relatively high theta frequency $(6-9 \mathrm{~Hz})$ reflecting the sniffing activity. $\boldsymbol{B}_{1}$, Evolution of the absolute gamma power from 40 min before to 120 min after injections of BIM-23627 (black squares, $n=20$ ), octreotide (gray squares, $n=20$ ), and saline (white circles, $n=18$ ). The zero time point corresponds to the injection (arrow). Inset, Evolution of the mean gamma frequency. "Repeated-measures ANOVA, drug versus saline, $p<0.05$; " unpaired $t$ test, $p<0.05 . B_{2 \prime}$ ( Comparison of the relative gamma power between "pre" (referring to the $-40 /-10$ min) and "post" (referring to the $+40 /+70 \mathrm{~min}$ ) time blocks (normalized to the total spectral power with "pre" block set at 1) for saline (white, $n=18$ ), BIM-23627 (black, $n=20$ ), octreotide (gray, $n=20$ ), and L-779976 (light gray, $n=16$ ). Paired $t$ test, ${ }^{* *} p<0.01,{ }^{* * *} p<0.001$. C, Relative gamma power between "pre" and "post" time blocks (normalized to the total spectral power) in wild-type (left part, $n=8$ ) and sst2 knock-out (right part, $n=8$ ) animals. $\boldsymbol{D}_{1}$, Evolution of the peak amplitude of the conditioning response (black circle) and the test response (black square) from 40 min before to 120 min after BIM-23627 injection $(n=10) . \boldsymbol{D}_{2}$, "Conditioning" (open arrowhead) and "test" (arrowhead) field potential responses in the EPL after L0T stimulation (arrow), before (solid line) and after (dashed line) BIM-23627 injection. $\boldsymbol{D}_{3}$, Paired-pulse ratio change between "pre" and "post" time blocks. *Paired $t$ test,$p<0.01$. Error bars indicate SEM.

tion of immunopositive cells in the MCL and their size suggest that sst2A-immunoreactive profiles correspond to mitral cells. To confirm this, agonist-induced internalization of sst $2 \mathrm{~A}$ receptors was examined in mitral cell bodies identified after tracer injection. Dextran-FITC injection in the glomerular layer (GL) anterogradely labeled several characteristic mitral cells (Fig. 1C,F,I, arrowheads) and a few MCL interneurons (Fig. $1 F$, open arrowheads). One hour after agonist injection, sst2A labeling was even more concentrated in large cell bodies in the MCL (Fig. 1D, G,J). Tracer-positive mitral cells were systematically immunopositive for sst2A (Fig. $1 E, H, K$, arrowheads), whereas tracer-positive interneurons were immunonegative (Fig. $1 \mathrm{H}$, open arrowheads).

Local injections of sst2-selective agonists and antagonist influence gamma oscillation power and dendrodendritic interaction in freely behaving mice

Activated assemblies of mitral cells typically engage in rhythmic synchronization in the gamma-frequency range (Lledo and
Lagier, 2006; Kay et al., 2009). Because of sst2A receptor localization in mitral cells, we hypothesized that endogenous somatostatin influences mitral cell properties and thus gamma oscillations. To test this, local injections of sst2-selective agonists and antagonist were coupled to LFP recordings in the MOB of awake mice during spontaneous exploratory activity. Typical olfactory LFP activity was composed of bursts of gamma oscillations $(40-100 \mathrm{~Hz})$, superimposed onto theta waves $(6-9 \mathrm{~Hz})$ associated with sniffing activity (Fig. $2 A_{1}, A_{2}$ ). A decrease in gamma power appeared 30 min after injection of BIM-23627, an sst2-selective antagonist, and lasted up to $120 \mathrm{~min}\left(F_{(16,576)}=7.53, p<0.0001\right)$ (Fig. $\left.2 A_{1}, A_{2}, B_{1}, B_{2}\right)$. Conversely, injection of octreotide, an sst2selective agonist, induced a delayed and long-lasting increase of gamma power $\left(F_{(16,576)}=4.34, p<0.0001\right)$ (Fig. $\left.2 B_{1}, B_{2}\right)$. Yet these effects did not reflect a global change of the whole spectral power. In the 40-70 min window after sst2-antagonist injection (Fig. $2 \mathrm{~B}_{2}$, "post" time block), the relative power of the gamma band, normalized to the total spectral power, still significantly decreased by 


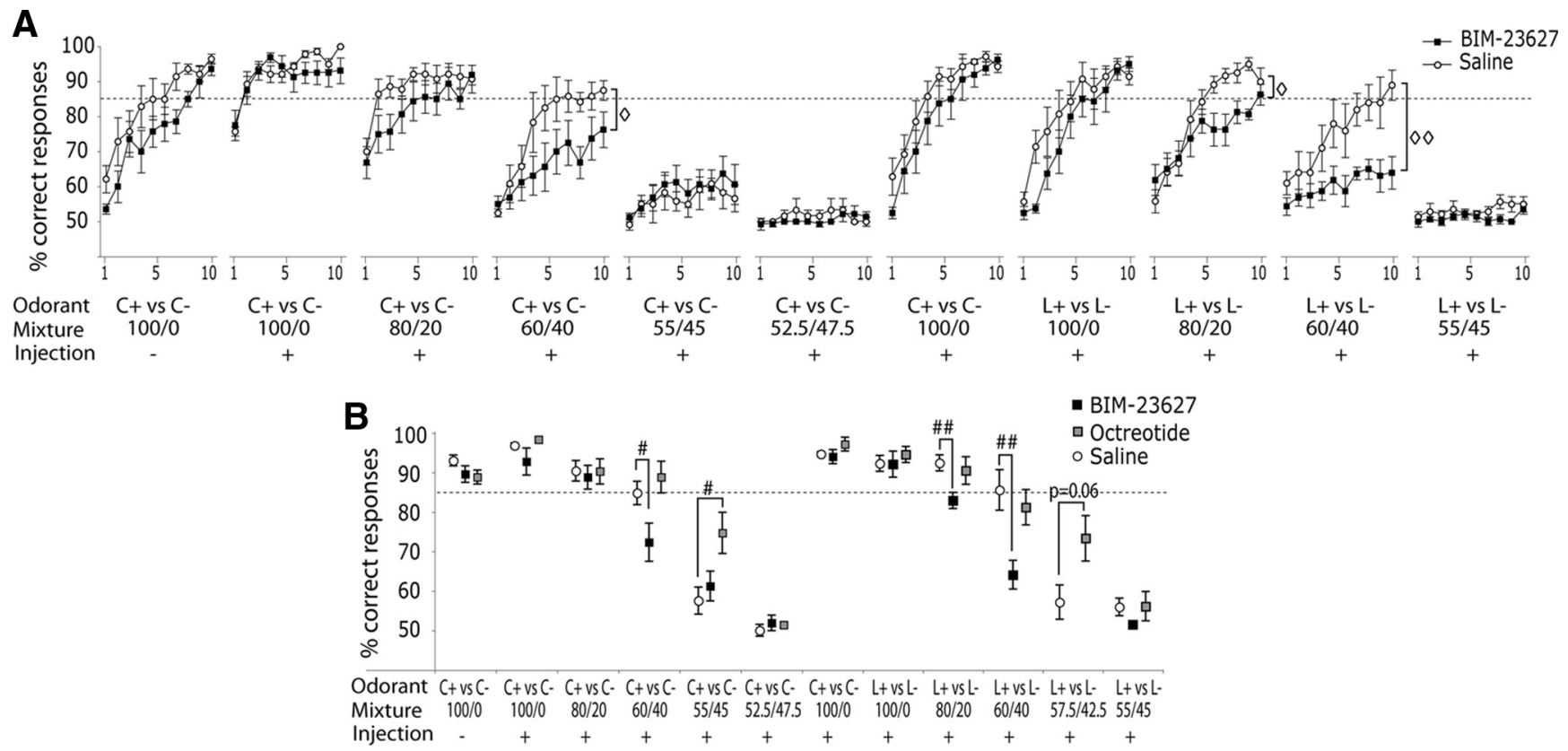

Figure 3. Bilateral injections of sst2-selective agonist or antagonist influence fine odor discrimination. $A$, Mean percentage of correct responses for each training block (saline, white circles, $n=$ 7; BIM-23627, black square, $n=8$ ). The odor pair, the odorant relative concentration (see supplemental Table S1, available at www.jneurosci.org as supplemental material) and the injection status are indicated below ( $C+/ C-$ and $\mathrm{L}+/ \mathrm{L}-$, respectively, for carvone and limonene enantiomers). Repeated-measure ANOVA, saline versus BIM-23627, $\diamond_{p}<0.05, \diamond \diamond_{p}<0.01 . B, A v e r a g e$ accuracy for the last three training blocks (saline, white circles, $n=7$; BIM-23627, black squares, $n=8$, octreotide gray squares, $n=7$ ). The odor pair, the odorant relative concentration, and the injection status are indicated below. Unpaired $t$ test, drug versus saline, ${ }^{\#} p<0.05,{ }^{\# \#} p<0.01$. Error bars indicate SEM.

$-33.6 \pm 6.8 \%$ in BIM-23627-injected mice $\left(t_{(19)}=4.93, p<\right.$ $0.0001)$ compared to "pre" time block, while octreotide-injected mice displayed an increase of $+36.2 \pm 11.4 \%\left(t_{(19)}=3.18, p=\right.$ 0.005). A similar effect was observed with L-779976, another sst2selective agonist (Fig. $\left.2 B_{2}\right)\left(+62.8 \pm 15.6 \%, t_{(15)}=4.01, p=0.001\right)$.

Drug treatments did not affect gamma frequency (Fig. $2 B_{1}$, inset) (frequency changes between "pre" and "post" blocks: $-0.8 \pm 0.3 \mathrm{~Hz},-0.8 \pm 0.4 \mathrm{~Hz}$, and $-1.4 \pm 0.5 \mathrm{~Hz}$ respectively for saline, BIM-23627 and octreotide, $p>0.1$ ). Power changes were specific to the gamma frequency band, as beta and theta oscillation powers remained unaffected (relative power changes between "pre" and "post" blocks, respectively for saline, BIM-23627 and octreotide: for beta oscillations, $-8.8 \pm 4.6 \%,-7.7 \pm 3.6 \%$, and $-0.1 \pm 3.3 \%, p>0.05$; for theta oscillations, $-6.1 \pm 9.8 \%$, $-14.4 \pm 7.1 \%,-7.2 \pm 6.0 \%, p>0.05)$. The phase relationship of gamma bursts with the sniff cycle, measured from autocorrelograms between gamma oscillation amplitude and theta rhythm, was not affected by drug injections (data not shown). In contrast to wild-type mice, gamma power was not affected by drug injection in sst 2 knock-out animals (Fig. 2C). Moreover, knock-out mice displayed a pronounced decrease in gamma power compared to wild-type animals $\left(-30.3 \pm 3.4 \%, t_{(15)}=3.01, p=\right.$ 0.009 ), without significant changes in the other frequency bands (data not shown).

Dendrodendritic synaptic interactions between mitral and granule cells support gamma oscillations (Lledo and Lagier, 2006; Kay et al., 2009). Sst2-mediated modulation of dendrodendritic synaptic transmission was investigated by recording LOT-evoked LFPs after paired stimulations. Typical evoked LFPs were composed of a pair of large negativity evoked by the first ("conditioning" response) and the second ("test" response) LOT stimulations (Fig. $2 \mathrm{D}_{2}$ ). This negativity reflects the activity of the mitral-togranule cell dendrodendritic excitatory synapses, and the diminution of amplitude of the "test" response reflects the level of inhibition in mitral cell evoked by the first "conditioning" stimulation (Mori and Takagi, 1978; Tsuno et al., 2008). BIM-23627 injection induced a delayed ( $\sim 30 \mathrm{~min})$ and long-lasting increase of the "conditioning" response (Fig. $\left.2 D_{1}\right)\left(+8.2 \pm 2.4 \%, t_{(9)}=\right.$ $3.37, p=0.008)$ and decrease of the "test" response $(-26.6 \pm$ $\left.8.3 \%, t_{(9)}=3.17, p=0.011\right)$, which resulted in a general decrease of the paired-pulse ratio (Fig. $\left.2 D_{3}\right)\left(-31.1 \pm 7.9 \%, t_{(9)}=3.92\right.$, $p=0.003)$.

\section{Odor discrimination performances are modified after} intrabulbar injection of sst2-selective agonist and antagonist Mice were trained to sample a pair of odorants and to lick only in response to the rewarded odorant. One day after reaching the performance criterion with a pair of enantiomers $[1 \%(+)$ carvone vs $1 \%(-)$-carvone], the same task was preceded by bilateral injections of BIM-23627, octreotide, or saline. Injections were done $37 \pm 1 \mathrm{~min}$ before the task, to take into account the 30-40 min delayed effects of the drugs on gamma power. Regardless of their treatment, mice discriminated the two odorants with maximal accuracy (Fig. 3). Then, mice had to discriminate between progressively more and more similar binary mixtures of carvone enantiomers, so that the difficulty of the olfactory discrimination task increased over sessions. Whereas octreotideand vehicle-injected mice succeeded in discriminating the 60/40 mixture, BIM-23627-injected mice failed to reach the performance criterion $\left[F_{(9,108)}=2.37, p=0.017\right.$ (Fig. $\left.3 A\right) ; t_{(12)}=2.2$, $p=0.048$ (Fig. $3 B$ ) . With the 55/45 mixture, octreotide-injected mice performed significantly better than controls $\left(F_{(9,90)}=2.12\right.$, $\left.p=0.035 ; t_{(12)}=2.35, p=0.036\right)$ (Fig. $3 B$ ). A new pair of monomolecular odorants $[1 \%(+)$-limonene vs $1 \%(-)$-limonene] was then tested to examine if drug treatments interfered with the acquisition of a novel odor-reward association. All drug-treated animals performed limonene enantiomer discrimination as well as controls. Mice were then asked to discriminate between pro- 
gressively more and more similar binary mixtures of limonene enantiomers. Compared to saline, BIM-23627 impaired odor discrimination with the $80 / 20\left[F_{(9,108)}=3.13, p=0.0022\right.$ (Fig. $\left.3 A) ; t_{(12)}=3.34, p=0.0059\right)($ Fig. $\left.3 B)\right]$ and the $60 / 40\left[F_{(9,108)}=\right.$ 2.76, $p=0.0063$ (Fig. $3 A$ ); $t_{(11)}=3.54 ; p=0.0046$ (Fig. $3 B$ )] mixtures. Conversely, octreotide-injected mice performed better than controls with the 57.5/42.5 mixture $\left(F_{(9,99)}=3.01, p=\right.$ $\left.0.0033 ; t_{(11)}=2.16, p=0.056\right)($ Fig. $3 B)$.

\section{Discussion}

In this study, we examined how the neuropeptide somatostatin influences olfactory processing. Mitral cell dendrites were identified as an action site of the peptide as they express sst2A, the full-length form of the sst 2 receptor. The selective blockade of sst 2 receptors enhanced dendrodendritic inhibition of mitral cell dendrites, decreased gamma oscillation power while sparing other frequency bands, and impaired odor discrimination. Conversely, sst2-selective agonists increased gamma oscillation power, and improved discrimination performances. Thus, endogenous release of somatostatin strongly influences gamma oscillation homeostasis, through the modulation of dendrodendritic synaptic properties, and contributes to olfactory processing.

\section{Somatostatin tone on mitral cell sst 2 receptors in the MOB}

Among the five somatostatin receptor subtypes, sst2, sst3, and sst4 are present in the MOB (Videau et al., 2003). The known pharmacological selectivity of the three agents used herein and the absence of drug effects in sst 2 knock-out animals suggest that the observed effects are essentially mediated by sst 2 receptors. The reduced gamma power, after pharmacological blockade or genetic deletion of sst 2 receptors, reveals the existence of a potent endogenous somatostatin tone on these receptors that may participate in the homeostasis of the reciprocal synapse by regulating synaptic transmission in mitral cells. In the MOB, sst2 receptors are mostly concentrated in the EPL and somatostatin is present in a subset of EPL interneurons (Lepousez et al., 2010) that receive high-frequency inputs from mitral cells (Hamilton et al., 2005). By analogy with hippocampal somatostatin-expressing cells during seizure (Vezzani and Hoyer, 1999; Baraban and Tallent, 2004), an elevated level of excitation of somatostatin interneurons induced by mitral cells may control peptide release that, in turn, would modulate the strength of the dendrodendritic synapse.

\section{Delayed and long-lasting effects on gamma oscillations and dendrodendritic inhibition}

In awake animals, changes in fast oscillations in the gamma range do not likely result from a variation of firing rate of individual neurons but rather reflect a dynamical state of mitral cell population firing patterns (Rinberg and Gelperin, 2006). Indeed, when animals perform correctly a discrimination task, gamma oscillations are enhanced (Beshel et al., 2007), whereas mitral cell responses are hardly detectable by measuring single-cell firing rate (Kay and Laurent, 1999; Doucette and Restrepo, 2008). Although the dendrodendritic synapse is essential for gamma oscillation generation, the physiological mechanisms underlying these oscillations are not well understood. Recent studies suggest that these oscillatory dynamics result from the interaction between the dendrodendritic synaptic transmission and intrinsic properties of both cell partners, such as subthreshold oscillations and spiking activity (Lledo and Lagier, 2006; Kay et al., 2009). Herein, we observed that gamma oscillation reduction after sst 2 receptor blockade is associated with an increase of dendrodendritic inhi- bition. Changes in the decay time but not in the amplitude of dendrodendritic inhibition tune the frequency of gamma oscillations (Lagier et al., 2007). Thus, the lack of sst2-mediated changes in oscillation frequency suggests that sst 2 receptors modulate the amplitude but not the kinetics of inhibition. As sst 2 receptors are localized in mitral cell dendrites, sst 2 activation could decrease mitral-to-granule cell glutamate release and consequently decrease GABA release from granule cells. Indeed, the increase of the conditioning response observed after blocking sst2 receptors supports an increase excitatory drive on granule cells that, in turn, could activate inhibitory synaptic transmission, as reported for acetylcholine (Ghatpande and Gelperin, 2009). In other brain regions, presynaptic modulation of glutamate release by sst 2 receptors results from the inhibition of voltage-gated calcium channels (VGCC) or from the activation of specific potassium channels such as A-type channels $\left(I_{\mathrm{A}}\right)$ (Baraban and Tallent, 2004; Viollet et al., 2008). In mitral cells, VGCC and $I_{\mathrm{A}}$ contribute to glutamate release (Lledo and Lagier, 2006), but whether they constitute potential effectors of sst 2 receptors remains to be tested. Alternatively, the decreased inhibition on mitral cells after sst 2 receptor activation could originate from a postsynaptic control of granule-to-mitral inhibitory transmission, as observed for dopamine (Brünig et al., 1999). In this latter study, a delayed and gradual upmodulation of $\mathrm{GABA}_{\mathrm{A}}$ receptors occurred in mitral cells after $\mathrm{D}_{2}$ receptor activation through $\mathrm{PKC}$-induced phosphorylation. Here, sst2-selective agonists and antagonist specifically affected gamma oscillations after $30 \mathrm{~min}$. This interval does not correspond to a diffusion delay, since injection of a chloride channel blocker affects LFP signal 5 min after injection (G. Lepousez, personal communication). Therefore, the delayed and long-lasting effects observed with somatostatin-related agents may develop slowly and durably, resulting from complex or indirect transduction pathways, the nature of which remains to be characterized. Similar delayed and long-lasting effects on gamma oscillations have already been observed in the MOB after noradrenergic agonist applications (Gire and Schoppa, 2008), and after cholinergic activation in the visual cortex (Rodriguez et al., 2004).

\section{A novel correlate between dendrodendritic transmission, network oscillations, and fine odor discrimination}

By increasing dendrodendritic inhibition, sst2-antagonist injection dramatically reduced gamma oscillation power, and significantly decreased odor discrimination of odor mixtures but not of monomolecular odorants. Conversely, sst2-agonists increased both gamma power and odor discrimination abilities. First, these results confirm the importance of the dendrodendritic reciprocal synapse in gamma oscillation generation. Herein, we observed that in awake mice, the increase of dendrodendritic inhibition after sst2 receptor blockade is associated with a reduction of gamma oscillation power. This contrasts with in vitro experiments in which a positive relationship between dendrodendritic inhibition amplitude and oscillation power has been reported (for review, see Lledo and Lagier, 2006). In vivo, somatostatin modulation of dendrodendritic inhibition may control the extent of action potential backpropagation in mitral cell dendrites (Xiong and Chen, 2002), thereby controlling the extent of lateral inhibition, and the level of synchrony and oscillations in the network. Interestingly, after noradrenaline application, a long-term increase in gamma power is also observed (Gire and Schoppa, 2008) and is thought to result from mitral cell disinhibition (Jahr and Nicoll, 1982). Second, our data confirm the importance of fast oscillatory population dynamics for the discrimination of 
highly similar stimuli, and the role of synchronization in pattern segmentation (Lledo and Lagier, 2006; Kay et al., 2009). Changes occurred in the gamma but not in the beta bands. LFP recording conditions (spontaneous activity) might have underestimated beta oscillation power, which is enhanced with learning (Ravel et al., 2003). Nevertheless, injections of sst2-ligands did not interfere with the acquisition of a novel odor-reward association, suggesting that beta oscillations, which are essential for a such association (Kiselycznyk et al., 2006), remained unaffected.

Somatostatin is involved in cognitive processes, and interestingly its concentration is decreased in several brain disorders associated with cognitive impairments (Epelbaum et al., 2009). The present data suggest that disturbance of endogenous levels of somatostatin impairs neural synchronization and consequently affects behavioral responses. Future research is needed to correlate intrinsic levels of somatostatin with pathological EEG modifications and cognitive deficits observed in brain disorders.

\section{References}

Adrian ED (1942) Olfactory reactions in the brain of the hedgehog. J Physiol 100:459-473

Baraban SC, Tallent MK (2004) Interneuron diversity series: interneuronal neuropeptides-endogenous regulators of neuronal excitability. Trends Neurosci 27:135-142.

Bassant MH, Simon A, Poindessous-Jazat F, Csaba Z, Epelbaum J, Dournaud P (2005) Medial septal GABAergic neurons express the somatostatin sst $2 \mathrm{~A}$ receptor: functional consequences on unit firing and hippocampal theta. J Neurosci 25:2032-2041.

Beshel J, Kopell N, Kay LM (2007) Olfactory bulb gamma oscillations are enhanced with task demands. J Neurosci 27:8358-8365.

Brünig I, Sommer M, Hatt H, Bormann J (1999) Dopamine receptor subtypes modulate olfactory bulb gamma-aminobutyric acid type A receptors. Proc Natl Acad Sci U S A 96:2456-2460.

Castillo PE, Carleton A, Vincent JD, Lledo PM (1999) Multiple and opposing roles of cholinergic transmission in the main olfactory bulb. J Neurosci 19:9180-9191.

Chaudhury D, Escanilla O, Linster C (2009) Bulbar acetylcholine enhances neural and perceptual odor discrimination. J Neurosci 29:52-60.

Csaba Z, Lelouvier B, Viollet C, El Ghouzzi V, Toyama K, Videau C, Bernard V, Dournaud P (2007) Activated somatostatin type 2 receptors traffic in vivo in central neurons from dendrites to the trans Golgi before recycling. Traffic 8:820-834.

Doucette W, Restrepo D (2008) Profound context-dependent plasticity of mitral cell responses in olfactory bulb. PloS Biol 6:e258.

Epelbaum J, Guillou JL, Gastambide F, Hoyer D, Duron E, Viollet C (2009) Somatostatin, Alzheimer's disease and cognition: an old story coming of age? Prog Neurobiol 89:153-161.

Gastambide F, Lepousez G, Viollet C, Loudes C, Epelbaum J, Guillou JL (2009) Cooperation between hippocampal somatostatin receptor subtypes 4 and 2: functional relevance in interactive memory systems. Hippocampus. Advance online publication. Retrieved July 21, 2009. doi:10.1002/hipo.20680.

Ghatpande AS, Gelperin A (2009) Presynaptic muscarinic receptors enhance glutamate release at the mitral/tufted to granule cell dendrodendritic synapse in the rat main olfactory bulb. J Neurophysiol 101:2052-2061.

Gire DH, Schoppa NE (2008) Long-term enhancement of synchronized oscillations by adrenergic receptor activation in the olfactory bulb. J Neurophysiol 99:2021-2025.

Hamilton KA, Heinbockel T, Ennis M, Szabó G, Erdélyi F, Hayar A (2005)
Properties of external plexiform layer interneurons in mouse olfactory bulb slices. Neuroscience 133:819-829.

Jahr CE, Nicoll RA (1982) Noradrenergic modulation of dendrodendritic inhibition in the olfactory bulb. Nature 297:227-229.

Kay LM, Laurent G (1999) Odor- and context-dependent modulation of mitral cell activity in behaving rats. Nat Neurosci 2:1003-1009.

Kay LM, Beshel J, Brea J, Martin C, Rojas-Líbano D, Kopell N (2009) Olfactory oscillations: the what, how and what for. Trends Neurosci 32:207-214.

Kiselycznyk CL, Zhang S, Linster C (2006) Role of centrifugal projections to the olfactory bulb in olfactory processing. Learn Mem 13:575-579.

Lagier S, Panzanelli P, Russo RE, Nissant A, Bathellier B, Sassoè-Pognetto M, Fritschy JM, Lledo PM (2007) GABAergic inhibition at dendrodendritic synapses tunes gamma oscillations in the olfactory bulb. Proc Natl Acad Sci U S A 104:7259-7264.

Lepousez G, Csaba Z, Bernard V, Loudes C, Videau C, Lacombe J, Epelbaum J, Viollet C (2010) Somatostatin interneurons delineate the inner part of the external plexiform layer in the mouse main olfactory bulb. J Comp Neurol, in press.

Lledo PM, Lagier S (2006) Adjusting neurophysiological computations in the adult olfactory bulb. Semin Cell Dev Biol 17:443-453.

Mandairon N, Peace S, Karnow A, Kim J, Ennis M, Linster C (2008) Noradrenergic modulation in the olfactory bulb influences spontaneous and reward-motivated discrimination, but not the formation of habituation memory. Eur J Neurosci 27:1210-1219.

Mori K, Takagi SF (1978) Activation and inhibition of olfactory bulb neurones by anterior commissure volleys in the rabbit. J Physiol 279:589-604.

Neville KR, Haberly LB (2003) Beta and gamma oscillations in the olfactory system of the urethane-anesthetized rat. J Neurophysiol 90:3921-3930.

Nusser Z, Kay LM, Laurent G, Homanics GE, Mody I (2001) Disruption of GABA(A) receptors on GABAergic interneurons leads to increased oscillatory power in the olfactory bulb network. J Neurophysiol 86:2823-2833.

Olias G, Viollet C, Kusserow H, Epelbaum J, Meyerhof W (2004) Regulation and function of somatostatin receptors. J Neurochem 89:1057-1091.

Ravel N, Chabaud P, Martin C, Gaveau V, Hugues E, Tallon-Baudry C, Bertrand O, Gervais R (2003) Olfactory learning modifies the expression of odour-induced oscillatory responses in the gamma $(60-90 \mathrm{~Hz})$ and beta $(15-40 \mathrm{~Hz})$ bands in the rat olfactory bulb. Eur J Neurosci 17:350-358.

Rinberg D, Gelperin A (2006) Olfactory neuronal dynamics in behaving animals. Semin Cell Dev Biol 17:454-461.

Rodriguez R, Kallenbach U, Singer W, Munk MH (2004) Short- and longterm effects of cholinergic modulation on gamma oscillations and response synchronization in the visual cortex. J Neurosci 24:10369-10378.

Tsuno Y, Kashiwadani H, Mori K (2008) Behavioral state regulation of dendrodendritic synaptic inhibition in the olfactory bulb. J Neurosci 28:9227-9238.

Vezzani A, Hoyer D (1999) Brain somatostatin: a candidate inhibitory role in seizures and epileptogenesis. Eur J Neurosci 11:3767-3776.

Videau C, Hochgeschwender U, Kreienkamp HJ, Brennan MB, Viollet C, Richter D, Epelbaum J (2003) Characterisation of [125I]-Tyr0DTrp8somatostatin binding in sst1- to sst4- and SRIF-gene-invalidated mouse brain. Naunyn Schmiedebergs Arch Pharmacol 367:562-571.

Viollet C, Lepousez G, Loudes C, Videau C, Simon A, Epelbaum J (2008) Somatostatinergic systems in brain: networks and functions. Mol Cell Endocrinol 286:75-87.

Xiong W, Chen WR (2002) Dynamic gating of spike propagation in the mitral cell lateral dendrites. Neuron 34:115-126.

Zheng H, Bailey A, Jiang MH, Honda K, Chen HY, Trumbauer ME, Van der Ploeg LH, Schaeffer JM, Leng G, Smith RG (1997) Somatostatin receptor subtype 2 knockout mice are refractory to growth hormone-negative feedback on arcuate neurons. Mol Endocrinol 11:1709-1717. 